\title{
Parents View About Oral Health Status, Oral Hygiene Behaviors, and Dental Services Utilization of Their Children With Hearing Impairment Attending Special Schools
}

\section{Soofia Rajabloo}

Golestan University of Medical Sciences and Health Services

Mina Pakkhesal ( $\sim$ m_pakkhesal@yahoo.com )

Golestan University of Medical Sciences and Health Services https://orcid.org/0000-0002-1043-836X

AliAkbar Naghavi Alhosseini

Golestan University of Medical Sciences and Health Services

\section{Zahra Ghorbani}

Shahid Beheshti University of Medical Sciences School of Dentistry

Abdolhalim Rajabi

Golestan University of Medical Sciences and Health Services

\section{Research note}

Keywords: oral health status, oral hygiene behavior, dental service utilization, hearing impairment, special school, parent view

Posted Date: May 13th, 2021

DOI: https://doi.org/10.21203/rs.3.rs-505933/v1

License: (c) (i) This work is licensed under a Creative Commons Attribution 4.0 International License.

Read Full License 


\section{Abstract}

Objectives: Parents are the principal decision-makers regarding their child's health. Awareness of parents' views regarding their children's health, particularly with special health care needs, is essential for health care providers. Therefore, the present study aimed to assess the parents' view about oral health status, oral hygiene practices, and dental services utilization of their children with hearing impairment attending special schools.

Results: $57.4 \%$ of the parents rated their children's oral health status as very good or good, $27.9 \%$ as moderate, and $9.0 \%$ as poor. About half of the parents (49.2\%) stated that their children used toothbrush once daily, and $15 \%$ use dental floss. Also, $54 \%$ of the children visited the dentist before this survey's conduct. The twice brush or more a day was significantly associated with the oral health status (OR: 22.16; $\mathrm{Cl} 95 \%$ ), and other factors did not show a significant association.

\section{Introduction}

Normal hearing is the ability to recognize, interoperate, and respond to verbal or noise stimuli by humans or animals capable of producing sounds. The terms "hearing impairment" and "hearing loss" indicate that the audiometric evaluation is below the standard hearing threshold, around 15 decibels (dBs). The term "deaf" is described in cases of severe or complete loss of hearing. This disability can either be inherited or acquired through time or disease process [1]. In March 2020 World Health Organization declared that Over $5 \%$ of the world's population (466 million people) has disabling hearing loss, which consisted of 432 million adults and 34 million children. Also, The majority of them live in low and middleincome countries [2]. Individuals with special health care needs (SHCN) have a higher risk of contracting certain oral diseases, such as dental cavities and gingivitis, and limited use of dental services can significantly affect these risks [3]. The lack of communication among the hearing impaired may lead to inequalities in healthcare access compared with the general population. Also, hearing-impaired subjects have poorer oral hygiene and use healthcare services than persons who are not impaired [4]. One essential tool for achieving good oral health is effective and efficient oral hygiene practices. Regular tooth brushing using fluoride-containing toothpaste at least twice a day is recommended to achieve and maintain good oral hygiene and prevent dental caries. The use of dental floss to clean interproximal surfaces is also crucial for effective plaque removal [5].

Dental care is the most common unmet health care need of disabled children. The disabled children's oral health may be neglected because of the disability condition, demanding diseases, or limited access to oral health care. It has been reported that dental treatment is the greatest unattended health need of the disabled [6]. This may be related to the barriers of seeking dental care, such as treatment cost, accessibility of facilities, fear of pain, acceptability of dentistry, and perception of dental need by children and parents [7]. 
Oral hygiene among children and young adults with hearing impairment was significantly associated with age, economic status, and parents' education, especially maternal education [8]. Low-education and low-income families do not pay enough attention to dental care and regular preventive visits, which could be caused dental caries to progress [9]. The nonattendance at the dentist of children with disabilities could be due to the low priority parents placed on their children with disabilities or the reduced importance of oral health [4]. Utilization studies serve as an important tool for oral health policy decisionmaking. By understanding these analyses, dentists will be better positioned to provide care and meet the needs of all persons with hearing impairment.

An awareness of parent perceptions regarding their children's oral health status, dental problems, and preventive dental care, especially with special health care needs, is essential for health care providers. Parents are the principal decision-makers regarding their child's health. Their perceptions can significantly influence preventive care and treatment choices and are important to a comprehensive understanding of the issues [10]. Parents are valuable advocates for their children, and they are capable of initiating solutions that can improve the habilitation process. Based on the parent's opinions, the following strategies offer service providers for children with hearing loss in developing countries recommendations to include in their service provisions that may improve parental involvement [11].

The present study was conducted to assess oral health status, oral hygiene practices, and dental services utilization patterns among subjects with hearing impairment attending special schools.

\section{Materials And Methods}

This observational cross-sectional study was conducted from May to September 2020 among 6 to 20 years old subjects with hearing impairment. Samples were selected from two special schools in Gorgan city of Golestan province, the north-eastern part of Iran. The list of special schools, the total number of students in each school, and written permission to perform investigation procedures were obtained from the local Education and Training Office. Here, the hierarchy of gatekeepers, such as the local authority responsible for special schools, managers, and teachers of schools, supported the researcher's access to the fieldwork site and legitimized the study. Besides, written consent was obtained from parents via an electronic signature in the virtual setting (WhatsApp).

A total of 76 children attended these special schools; 61 were in the appropriate age group. All participants were informed about the study aim by the special schools' assistant director before the survey. On the other hand, before the interview, it was established that each participant understood the purpose of the interview and was happy to proceed.

The present study was approved by the Research Ethics Committee of Golestan University of Medical Sciences (IR.GOUMS.REC.1398.343) and performed entirely following Helsinki's Declaration. All participants' rights were protected. Moreover, the data were handled anonymously and confidentially in all stages of the research. Consequently, all documents were de-identified using a participant code, and the names of individuals were removed. 
Data on demographic characteristics, medical history, and hearing impairment severity were collected from archives in the schools. Moreover, each parent take part in a 15-20 minutes' telephone interview. All interviews were accomplished by a single researcher using topic guide questions utilized in Jin \& Daly's study [12].

Subsequently, students' oral health status was rated (good/ very good, moderate, poor) according to parental response to "How would you describe the health of your child's mouth, teeth, and gums?". The second section asked parents about oral hygiene practices, e.g., tooth brushing frequency per day and dental floss usage by their children. Besides, previous dental visits and reasons for those visits were asked to obtain their dental care utilization pattern. Finally, a researcher asked about parents' experienced problems related to the utilization of dental services for their children.

The frequencies of variables were obtained by descriptive statistical analysis. Comparisons of the variables were conducted using Fisher's exact test or chi-square test, as appropriate. Univariate logistic regression was used to determine which factors significantly associated with oral health status, as defined by odds ratios (ORs) with $95 \%$ confidence intervals. P-values less than 0.05 were considered to be statistically significant. All analyses were performed using the statistical software STATA version 16 (Stata Corp, College Station, TX).

\section{Results}

A total of 61 students with hearing impairment, 38 males and 23 females, aged between 6 to 20 years (mean age \pm SD: $15.70 \pm 3.60$ ), participated in the study. The study population's demographic characteristics such as age, gender, race, and school level were illustrated in Table 1. 
Table 1

Demographic characteristics of students with hearing impairment attending special schools from parents' views $(\mathrm{n}=61)$

\begin{tabular}{|c|c|c|}
\hline variables & & Number (\%) \\
\hline \multicolumn{3}{|l|}{ Gender } \\
\hline & Male & $38(62.3)$ \\
\hline & Female & $23(37.7)$ \\
\hline \multicolumn{3}{|c|}{ Age (in years) } \\
\hline & $6-15$ & $23(37.7)$ \\
\hline & $>15$ & $38(62.3)$ \\
\hline \multicolumn{3}{|l|}{ Race } \\
\hline & Fars & $27(44.3)$ \\
\hline & Turkmen & $18(29.5)$ \\
\hline & Sistani & $16(26.2)$ \\
\hline \multicolumn{3}{|c|}{ Mother Education level } \\
\hline & Illiterate & $4(6.6)$ \\
\hline & Elementary & $34(55.7)$ \\
\hline & High school and more & $23(37.7)$ \\
\hline \multicolumn{3}{|c|}{ Father Education level } \\
\hline & Illiterate & $8(13.1)$ \\
\hline & Elementary & $21(34.4)$ \\
\hline & High school and more & $32(52.5)$ \\
\hline \multicolumn{3}{|c|}{ Maternal occupation } \\
\hline & Housekeeper & $56(91.8)$ \\
\hline & Voluntary worker & $3(4.9)$ \\
\hline & Employee & $2(3.3)$ \\
\hline \multicolumn{3}{|c|}{ Paternal occupation } \\
\hline & Does not work & $1(1.6)$ \\
\hline & Voluntary worker & $16(26.2)$ \\
\hline & Employee & $4(6.6)$ \\
\hline
\end{tabular}




\begin{tabular}{|lll|}
\hline variables & Number (\%) \\
\hline Student's education level & & $40(65.6)$ \\
& Elementary & $18(29.5)$ \\
& Secondary & $26(42.6)$ \\
& High & $17(27.9)$ \\
\hline
\end{tabular}

About half of the parents (49.2\%) stated that their children used toothbrush once a day, and $15 \%$ use dental floss. Moreover, $57.4 \%$ of the parents rated their children's oral health status as very good or good, $27.9 \%$ as moderate, and $9.0 \%$ as poor (Table 2 ).

Table 2

Distribution of oral health behaviors and oral health status among students with hearing impairment attending special schools from parents' views

\begin{tabular}{|lll|}
\hline Variables & \multicolumn{2}{l|}{ Number (\%) } \\
\hline Tooth brushing & & \\
\hline & Twice or more a day & $22(36.1)$ \\
\hline & Once a day & $30(49.2)$ \\
\hline Dental flossing & Some times & $9(14.8)$ \\
\hline & Yes & $15(24.6)$ \\
\hline Sweet meal intake & No & $46(75.4)$ \\
\hline & never & $10(16.4)$ \\
\hline & Some times & $21(34.4)$ \\
\hline & One time or more a day & $30(49.2)$ \\
\hline Oral health status & & $35(57.4)$ \\
\hline & Good/ very good & $17(27.9)$ \\
\hline & Moderate & $9(14.8)$ \\
\hline & Poor & \\
\hline
\end{tabular}


The results also showed that only $54 \%$ of the participants visited the dentist before this survey. More than half of these visits (66.7\%) were due to dental problems (Table 3 ).

Table 3

Frequency distribution of dental care utilization pattern among students with hearing impairment attending special schools from parents' views

\begin{tabular}{|lll|}
\hline Variables & & Number (\%) \\
\hline Last dental visit & & \\
\hline & Less than 6 months ago & $13(21.2)$ \\
\hline & $6-12$ months ago & $6(9.8)$ \\
\hline & 1year and more & $14(23.0)$ \\
\hline & No visit & $28(46.0)$ \\
\hline Cause of last dental visit & & \\
\hline & Dental pain/ oral \& gingival problems & $22(36.0)$ \\
& Routine check-up & $9(14.8)$ \\
\hline & Do not know / forgotten & $2(3.2)$ \\
\hline & No visit & $28(46.0)$ \\
\hline
\end{tabular}

Related to barriers of dental services utilization, $34.4 \%$ of parents reported "no need for the use of dental services", 27.9\% "no problem in dental visits", 26.2\% had "cost difficulties", 9.8\% " insurances do not cover dental costs" and $1.6 \%$ "dentists " unwillingness". Moreover, dental services utilization was not significantly associated with study variables. However, twice brush or more a day than sometimes brush significantly associated with the oral health status (OR: 22.16; CI 95\%: 161.83-3.03), and other factors did not show a significant association.

\section{Discussion}

Oral health is essential to all persons' health and well-being, especially those with disabilities, because they have more significant oral health needs. In the present study, oral health status, oral hygiene practices, and dental services utilization patterns were assessed among pupils with hearing impairment attending special schools. Our results revealed that a good proportion (57.4\%) of the parents rated their children's oral health status as very good or good, and approximately half of the students (46\%) don't have dental services utilization. Also, about half of the students (49\%) brush their teeth once daily, have sweet meal intake one time or more a day, and most participants do not use dental floss. Our study's findings among hearing-impaired students are unexpected and may not represent hearing-impaired young adults in general. The participants in our investigation were studying in special schools with a 
perfect organization. There may be specific characteristics that influenced this group's oral health behaviors compared to other hearing-impaired students. Likewise, the Vichayanrat study showed hearing impairment did not appear to affect the prevalence of oral health conditions and behaviors than those with normal hearing [8]. The Oredugba study results showed that only $12 \%$ of a group of deaf adolescents had received dental care in Nigeria. Ninety-four percent brushed their teeth once daily, and the majority of pupils (60\%) preferred biscuits and soft drinks as snacks [13]. Controversy, the other study in a special senior high school of East China illustrated a relatively lower proportion of dental health knowledge and lower proper dental health behavior among deaf students than the control group [14].

The use of dental services has been the attention of several studies between different ages and populations [15-19]. In the present study, we found that $45.9 \%$ of students had never visited the dentist yet, but in a study in India, $80.26 \%$ of the participants had never visited the dentist for a check-up or treatment [20]. Too, in our study, $66.7 \%$ of dental visits were because of dental pain or other mouth and gingiva problem rather than a routine checkup. In other words, dental services utilization was almost limited to urgent practices instead of preventive care. It was maybe due to low priority of oral health compared to hearing impairment, lack of knowledge, the problem in costs, etc. Similarly, in the Kumar et al. study, most subjects had no dental visit for a check-up or treatment [4]. In this way, some studies showed that children with developmental disabilities face even more perceived barriers to care based on family income and socioeconomic status [21-23].

\section{Limitations}

The first limitation of this study was the possibility of recall bias since parents may inaccurately respond to the questions. The second limitation was the socially desirable response bias, which was the interviewee's tendency to give overly positive responses.

\section{Abbreviations}

SHCN: Special Health Care Needs

\section{Declarations}

\section{Acknowledgments:}

The authors thank all parents for joining the study and their support in answering the telephone interview.

\section{Authors' contributions:}

SR and MP conceived the study idea and designed the work, SR led data collection, SR, MP, and AN led the writing, MP and ZG interpreted the data and revised manuscript, and AR led statistical analysis. All authors read, edited, and approved the final manuscript. 


\section{Disclosure of interest:}

The authors report no conflict of interest.

\section{Ethics approval and consent to participate:}

The Research Ethics Committee of Golestan University of Medical Sciences (IR.GOUMS.REC.1398.343) approved the present study. Accordingly, written permission was obtained from a hierarchy of gatekeepers, such as the local authority responsible for special schools in the area. Besides, written consent was obtained from parents via an electronic signature in the virtual setting (WhatsApp).

\section{Consent for publication:}

Not applicable.

\section{Availability of data and materials:}

The datasets used and analyzed during the current study are available from the corresponding author on reasonable request.

\section{Competing interests:}

The authors declare no conflicts of interest.

\section{Funding:}

Not applicable.

\section{References}

1. Alkahtani FH, Baseer MA, Ingle NA, Assery MK, Al Sanea JA, AlSaffan AD, et al. Oral Health Status, Treatment Needs and Oral Health Related Quality of Life among Hearing Impaired Adults in Riyadh City, Saudi Arabia. The journal of contemporary dental practice. 2019;20(6):744.

2. Organization WH. Deafness and hearing loss 2020 [updated 1 March 2020.

3. da Silva Júnior IF, Stüermer VM, Hartwig AD, Scharsdosim LR, Azevedo MS. Use of dental care services and related factors in students with special health care needs in a rehabilitation and education center. RSBO. 2018;15(1):5-11.

4. Kumar S, Dagli RJ, Mathur A, Jain M, Duraiswamy P, Kulkarni S. Oral hygiene status in relation to sociodemographic factors of children and adults who are hearing impaired, attending a special school. Special Care in Dentistry. 2008;28(6):258-64.

5. Olusile AO, Adeniyi AA, Orebanjo O. Self-rated oral health status, oral health service utilization, and oral hygiene practices among adult Nigerians. BMC oral health. 2014;14:140. 
6. Bhardwaj VK, Fotedar S, Sharma KR, Luthra RP, Jhingta P, Sharma D. Dentition status and treatment needs among institutionalized hearing and speech impaired children in Himachal Pradesh in India: A cross-sectional study. SRM Journal of Research in Dental Sciences. 2014;5(2):78.

7. Oredugba FA. Oral health care knowledge and practices of a group of deaf adolescents in Lagos, Nigeria. Journal of public health dentistry. 2004;64(2):118-20.

8. Vichayanrat T, Kositpumivate W. Oral health conditions and behaviors among hearing impaired and normal hearing college students at Ratchasuda College, Nakhon Pathom, Thailand. The Southeast Asian journal of tropical medicine and public health. 2014;45(5):1228-35.

9. Saldūnaitė K, Bendoraitienė EA, Slabšinskienė E, Vasiliauskienè I, Andruškevičienè V, Zūbienè J. The role of parental education and socioeconomic status in dental caries prevention among Lithuanian children. Medicina. 2014;50(3):156-61.

10. Kenney MK, Kogan MD, Crall JJ. Parental perceptions of dental/oral health among children with and without special health care needs. Ambulatory Pediatrics. 2008;8(5):312-20.

11. Alduhaim A, Purcell A, Cumming S, Doble M. Parents' views about factors facilitating their involvement in the oral early intervention services provided for their children with hearing loss in Kuwait. International journal of pediatric otorhinolaryngology. 2020;128:109717.

12. Jin EY, Daly B. The self-reported oral health status and behaviors of adults who are deaf and blind. Special Care in Dentistry. 2010;30(1):8-13.

13. Oredugba FA. Oral health care knowledge and practices of a group of deaf adolescents in Lagos, Nigeria. Journal of public health dentistry. 2004;64(2):118-20.

14. Wei H, Wang YL, Cong XN, Tang WQ, Wei PM. Survey and analysis of dental caries in students at a deaf-mute high school. Research in developmental disabilities. 2012;33(4):1279-86.

15. Medina-Solís CE, Maupomé G, Ávila-Burgos L, Hijar-Medina M, Segovia-Villanueva A, Pérez-Núñez R. Factors influencing the use of dental health services by preschool children in Mexico. Pediatric dentistry. 2006;28(3):285-92.

16. Sugihara N, Tsuchiya K, Hosaka M, Osawa H, Yamane G-y, Matsukubo T. Dental-care utilization patterns and factors associated with regular dental check-ups in elderly. The Bulletin of Tokyo Dental College. 2010;51(1):15-21.

17. Wu B, Tran TV, Khatutsky G. Comparison of utilization of dental care services among Chinese-and Russian-speaking immigrant elders. Journal of public health dentistry. 2005;65(2):97-103.

18. Barnett $S$, Franks P. Health care utilization and adults who are deaf: relationship with age at onset of deafness. Health services research. 2002;37(1):103.

19. Champion J HR. Paediatric dentistry: Dental care for children and young people who have a hearing impairment. . British dental journal 2000;189(3).

20. Suma G, Das UM, Akshatha B. Dentition status and oral health practice among hearing and speechimpaired children: A cross-sectional study. International journal of clinical pediatric dentistry. 2011;4(2):105. 
21. Schultz ST, Shenkin J, Horowitz A. Parental perceptions of unmet dental need and cost barriers to care for developmentally disabled children. Pediatric dentistry. 2001;23(4):321-5.

22. Purohit BM, Acharya S, Bhat M. Oral health status and treatment needs of children attending special schools in South India: a comparative study. Special Care in Dentistry. 2010;30(6):235-41.

23. Boss EF, Niparko JK, Gaskin DJ, Levinson KL. Socioeconomic disparities for hearing-impaired children in the united states. The Laryngoscope. 2011;121(4):860-6. 